\title{
Impact of Soy Bean on Thyroid Hormones of Albino Rats
}

\section{Nwachoko $\mathbf{N}^{*}$ and Jack IR}

Department of Chemistry, Rivers State University of Science and Technology, Nigeria

\begin{abstract}
Soy foods are traditional staples of Asian diets. Soy bean and thyroid health have focused on one specific category of nutrient-Isoflavones found in soy bean. This study examined the impact of soy bean on thyroid hormones which are thyroid stimulating hormone (TSH), tri-iodothyronine $\left(\mathrm{T}_{3}\right)$ and thyroxine $\left(\mathrm{T}_{4}\right)$ in albino rats. This was carried out in two phases. The rats were grouped in both phases of four groups, three rats in each group. The first phase was by feeding the animals at varying percentage $(30,50$ and 70$)$ for two weeks, while the second phase was by administration of soybean extract at $(500,1000$ and $2000 \mathrm{mg} / \mathrm{kg})$ respectively for same duration. The result obtained showed that thyroid hormones values for the fed groups were not significantly $(p<0.05)$ different with that of the control group. Also the result obtained for phase two showed that thyroid hormones values of the treated groups were not significantly $(p<0.05)$ different with that of the control group. The result for both phases showed that soy bean has no significant impact on the thyroid hormones levels of albino rates.
\end{abstract}

Keywords: Soy bean; Stimulating hormone (TSH); Tri-iodothyronine $\left(\mathrm{T}_{3}\right)$; Thyroxine $\left(\mathrm{T}_{4}\right)$

\section{Introduction}

Soy foods are traditional staples of Asian diets but because of their purported health benefits they have become popular in recent years among non-Asians. There are many bioactive soybean components that may contribute to the hypothesized health benefits of soy but attention has been focused on the isoflavones, which have both hormonal and nonhormonal properties [1,2]. Isoflavones are phytonutrients that belong to the much larger phytonutrient family called flavonoids. Most foods contain flavonoids, and many vegetables are especially rich in this family of phytonutrients. Isoflavones are produced via a branch of the general phenylpropanoid pathway that produces flavonoid compounds in higher plants [3]. Soybean is the most common source of isoflavones in human food. The major isoflavones in soybean are genistein and daidzein. The thyroid gland is responsible for the production of hormones involved in regulating metabolism, body weight and oxygen requirement as well as normal growth and development during childhood. The thyroid hormones (tri-iodothyronine $\left(\mathrm{T}_{3}\right)$ and thyroxine $\left(\mathrm{T}_{4}\right)$ are synthesized in the gland from iodine and the amino acid tyrosine [4-6]. At the molecular and biochemical levels, isoflavones have the ability to change thyroid cell events in at least two ways. First, isoflavones can interfere with activity of an enzyme called thyroid peroxidase (TPO). TPO helps in attaching iodine to the amino acid called tyrosine. This iodine-tyrosine combination forms the basis for the production of the thyroid hormone. Isoflavones act as alternative substrate for iodination. When this happens, concentration of thyroid hormones would reduce and potentially stimulate the production of thyroid stimulating hormones (TSH) [7-9]. Secondly, by interaction with thyroid binding globulin (TBG). This is a plasma protein involved in the inactivation and transport of $\mathrm{T}_{3}$ and $\mathrm{T}_{4}$. It has been hypothesized that phytoestrogens could potentially increase TBG concentrations. Any such increase could increase the binding capacity for thyroxine thus lowering free thyroxine concentration. In turn, TSH secretion would increase as the body attempts to restore free thyroxine concentration [10].

\section{Methodology}

\section{Sample collection}

Soybean was purchased from Mile III market, Diobu Port Harcourt,
Rivers State, Nigeria. The plants were identified using both botanical and local names to ensure that this work was done on the sample species.

\section{Sample preparation}

Soybean seed was separated from the shelves and ground using blender to get a smooth powdered form and was stored in an air tight polyethylene bag.

\section{Extraction of soybean}

The plants were extracted by filtration method. $200 \mathrm{~g}$ of the powdered sample were weighed using weighing balance and it was poured into $2000 \mathrm{ml}$ beaker, $1000 \mathrm{ml}$ of warm water was added and stirred properly. The solution was kept for $1 \mathrm{~h}$ and thereafter filtered using filter paper and creamy extract was obtained. The extracted component was poured into a beaker and concentrated with water bath at $60^{\circ} \mathrm{C}$.

\section{Experimental design}

Phase 1: Following the acclimatization period of one week, the animals were grouped into (4) four groups of three (3) animals in each group. They were fed with ground soybean mixed with rat feed.

Group 1: This group served as the control group and was kept on basal diet.

Group 2: They were fed on 30\% ground soybean $70 \%$ rat feed.

Group 3: They were fed on 50\% ground soybean 50\% rat feed.

Group 4: They were fed on 70\% ground soybean 30\% rat feed.

These rats were fed once daily for a period of two weeks.

*Corresponding author: Nwachoko N, Department Of Chemistry, Rivers State University of Science and Technology, Nigeria, Tel: +2349038858167; E-mail: blessedconfidence@yahoo.com

Received: August 12, 2017; Accepted: September 19, 2017; Published September 28, 2017

Citation: Nwachoko N, Jack IR (2017) Impact of Soy Bean on Thyroid Hormones of Albino Rats. Biochem Anal Biochem 6: 337. doi: 10.4172/2161-1009.1000337

Copyright: () 2017 Nwachoko N, et al. This is an open-access article distributed under the terms of the Creative Commons Attribution License, which permits unrestricted use, distribution, and reproduction in any medium, provided the original author and source are credited. 
Phase II: After acclimatization period of one week, the animals were grouped into four of three animals in each group and were treated orally with concentrated soybean extract.

Group 1: This group served as the control group and they were kept on basal diet.

Group 2: They were administered $500 \mathrm{mg} / \mathrm{kg}$ of plant extract.

Group 3: They were administered $1000 \mathrm{mg} / \mathrm{kg}$ of plant extract.

Group 4: They were administered $2000 \mathrm{mg} / \mathrm{kg}$ of plant extract.

The rats were treated once daily for a period of two weeks.

\section{Determination of TSH}

- $0.1 \mathrm{ml}$ of standard, sample and control was pipetted into appropriate wells.

- $0.1 \mathrm{ml}$ of conjugated reagent was added into each well, mixed thoroughly for 30 seconds to ensure a complete mixing, and then incubate at room temperature $\left(18-25^{\circ} \mathrm{C}\right)$ for $60 \mathrm{~min}$.

- After incubation, $0.1 \mathrm{ml}$ of TMB reagent was dispensed into each well and mixed gently for $10 \mathrm{~min}$ then incubate at room temperature in the dark for $20 \mathrm{~min}$ without shaking, the reaction was stopped by adding $0.1 \mathrm{ml}$ of stop solution on each well and mixed gently for 30 seconds, then the absorbance was read at $450 \mathrm{~nm}$.

\section{Procedure of Triodo Thyronine $\left(\mathrm{T}_{3}\right)$}

- $0.05 \mathrm{ml}$ of standard sample and control was pipetted into appropriate wells

- $0.05 \mathrm{ml}$ of anti-body reagent was added into each well and, mixed thoroughly for 30 seconds to ensure a complete mixing, and then incubate at room temperature $\left(18-25^{\circ} \mathrm{C}\right)$ for $60 \mathrm{~min}$.

- After incubation, $0.1 \mathrm{ml}$ of TMB reagent was dispensed into each well and mixed gently for $10 \mathrm{~min}$ then incubate at room temperature in the dark for $20 \mathrm{~min}$ without shaking, the reaction was stopped by adding $0.1 \mathrm{ml}$ of stop solution on each well and mixed gently for 30 seconds, then the absorbance was read at $450 \mathrm{~nm}$.

\section{Procedure of Thyroxine $\left(\mathrm{T}_{4}\right)$}

- $0.025 \mathrm{ml}$ of standard sample and control was pipetted into appropriate wells.

- $0.1 \mathrm{ml}$ of conjugated reagent was added into each well and mixed thoroughly for 30 seconds to ensure complete mixing. Then incubate at room temperature $\left(18-25^{\circ} \mathrm{C}\right)$ for $60 \mathrm{~min}$.

- After incubation, $0.1 \mathrm{ml}$ of TMB reagent was dispensed into each well and mixed gently for $10 \mathrm{~min}$ then incubate at room temperature in the dark for $20 \mathrm{~min}$ without shaking, the reaction was stopped by adding $0.1 \mathrm{ml}$ of stop solution on each well and mixed gently for 30 seconds, then the absorbance was read at $450 \mathrm{~nm}$.

\section{Result}

Table 1 showed the impact of soybeans on serum level of thyroid hormones ( $\mathrm{TSH}, \mathrm{T}_{3}, \mathrm{~T}_{4}$ ) of male and female albino rats fed with soybean for two weeks at varying percentage.

Table 2 showed the impact of oral cavage of soybeans on serum

\begin{tabular}{|c|c|c|c|}
\hline Groups & TSH $(\boldsymbol{\mu l} / \mathbf{m l})$ & T3 $(\mathbf{n g} / \mathbf{m l})$ & T4 $(\boldsymbol{\mu g} / \mathbf{d l})$ \\
\hline Group 1 Control & $1.03+0.66$ & $1.36+0.21$ & $3.81+0.51$ \\
\hline Group 2 & $1.46+0.28$ & $1.43+0.15$ & $3.23+0.21$ \\
\hline Group 3 & $1.22+0.36$ & $1.13+0.11$ & $2.81+0.21$ \\
\hline Group 4 & $1.51+0.33$ & $1.33+0.15$ & $2.96+0.46$ \\
\hline
\end{tabular}

Table 1: Thyroid hormones level of albino rats fed with soybean (Phase I).

\begin{tabular}{|c|c|c|c|}
\hline Groups & TSH $(\boldsymbol{\mu l U} / \mathbf{m l})$ & T3 $(\mathbf{n g} / \mathbf{m l})$ & $\mathbf{T 4}(\boldsymbol{\mu g} / \mathbf{d l})$ \\
\hline Group 1 control & $0.53+0.06$ & $0.83+0.06$ & $3.81+0.25$ \\
\hline Group 2 & $0.61+0.06$ & $0.83+0.06$ & $4.13+0.15$ \\
\hline Group 3 & $0.61+0.06$ & $0.83+0.06$ & $4.07+0.21$ \\
\hline GROUP 4 & $0.63+0.06$ & $0.87+0.06$ & $3.91+0.35$ \\
\hline
\end{tabular}

Table 2: Thyroid hormones level of albino rats administered with soybean extract (Phase II).

level of thyroid hormones (TSH, $\mathrm{T}_{3}, \mathrm{~T}_{4}$ ) of male and female albino rats induced with soybean extract.

\section{Discussion}

In this present study, thyroid hormones level of male and female albino rats were investigated.

Table 1, showed the serum thyroid hormones level of male and female albino rats fed with soybean at varying percentage $(30,50,70)$. Comparing the result of the control (group 1) and the fed groups, there was no significant increase $(p<0.05)$ in the thyroid hormones values of the fed groups.

Table 2, showed the serum thyroid hormones level of male and female albino rats administered with soybean extract at $(500,1000$, $2000 \mathrm{mg} / \mathrm{kg}$ ) respectively. Comparing the result of the control (group 1) and the treated groups, there was no significant increase in the thyroid hormones values of the treated groups.

Several scientific reports have supported the claim that soybean and its isoflavones increases the thyroid hormones levels, there are some reports indicating limited impact of soybean on thyroid hormones concentration. De Souza dos Santos et al. [11] reported a limited impact of soybean on thyroid hormones levels. Small scale study at the impact of $141 \mathrm{mg}$ of dietary isoflavones from soy protein isolate showed no impact on thyroid measurement. Lisa et al. [12] reported that rats feed with soy extract had no inhibitory effect on iodine uptake in albino rats. Additional factor might combine with soy isoflavonoes intake to put the thyroid at added risk. From nutritional standpoint, the most likely factor is iodine deficiency.

\section{Recommendation}

Based on this study, it is recommend that individuals should take soybean as one of the alternative source of proteins and those with history of iodine deficiency should seek the advice of their Healthcare Provider.

\section{Acknowledgement}

The authors appreciate the effort of Lively Stone Lab and Egbujor, Christiana Amarachi.

\section{References}

1. Kaufman PB, Duke JA, Brielmann H, Boik J, Hoyt JE (1997) A comparative survey of leguminous plants as sources of the isoflavones, genistein and daidzein: implications for human nutrition and health. Journal of Alternative Complement Medicine 3: 7-12.

2. Heber D, Berdanier CD, Dwyer JT, Feldman EB (2008) Plant Foods and phytochemicals in human health. CRC Press, pp: 176-181. 
Citation: Nwachoko N, Jack IR (2017) Impact of Soy Bean on Thyroid Hormones of Albino Rats. Biochem Anal Biochem 6: 337. doi: 10.4172/21611009.1000337

3. Thrope-Beeston JG, Nicolaides KH, McGregor AM (1992) Fetal thyroid function. Hormone 2: 207-217.

4. Gaitan E, Lindsay RH, Reichert RD, Ingbar SH, Cooksey RC, et al. (1989) Antithyroid and goitrogenic effects of miller: role of C-glycosylflavones. Journal of Clinical Endocrine Metabolism 68: 707-714.

5. Balmir F, Staack R, Jeffrey E, Jimenez MD, Wang L, et al. (1996) An extract of soy flour influences serum cholesterol and thyroid hormones in rats and hamsters. Journal of Nutrition 126: 3046-3053.

6. Sartelet H, Serghat S, Lobstein A, Ingenbleek Y, Anton R, et al. (1996) Flavonoids extracted from fonio millet (Digitaria exilis) reveal potent antithyroid properties. Nutrition 12: 100-106.

7. Rang HP, Dale MM (1987) Pharmacology. Churchill Livingston, UK, pp: 369-378
8. Divi RL, Doerge DR (1996) Inhibition of peroxidase by dietary flavonoids. Chemical Toxicology 9: 16-23.

9. Divi RL, Chang HC, Doerge DR (1997) Anti-thyroid isoflavones from soybean Biochemical Pharmacology 54: 1087-1096.

10. Ikeda T, Nishikawa A, Imazawa T, Kimura S, Hirose M (2000) Dramatic synergism between excess soybean intake and iodine deficiency on the development of rat thyroid hyperplasia. Carcinogenesis 21: 707-713.

11. De Souza dos Santos Mc, Goncalves CFL, Vaisman M (2011) Impact of flavonoids on thyroid function. Food and Chemical Toxicology 49: 2495-2502.

12. Lisa T, Mariam H, Carla W, Chao WX (2013) Soy extracts suppressed iodine uptake and stimulated the production of autoimmunogen in rat thyrocytes. Experimental Biology Medicine 238: 623. 